\title{
A POLICIZAÇÃO DA JUSTIÇA: UMA ANÁLISE SOBRE A HIPÓTESE DE FOUCAULT NO SISTEMA DE JUSTIÇA CRIMINAL BRASILEIRO A PARTIR DO DIREITO AO CONTRADITÓRIO
}

\author{
Antonio Eduardo Ramires Santoro* \\ Natália Lucero Frias Tavares ${ }^{* *}$
}

\begin{abstract}
Resumo:
A partir da hipótese apresentada por Michel Foucault de que a Justiça está a serviço da polícia, este trabalho pretende responder à pergunta se essa assertiva se verifica no Brasil, configurando-se seu problema central. Para realizou-se uma pesquisa sobre o sistema processual penal de garantias no Brasil, bem como as formas peculiares de produção de informações por meio de provas conforme os desenhos processuais penais que se apresentam na prática judicial brasileira. Confirmou-se a hipótese de Foucault em razão do uso demasiado de informações produzidas na fase policial ou pela oitava de policiais nas decisões judiciais.
\end{abstract}

Palavras-chave: hipótese de Foucault; policização da Justiça; sistema de justiça criminal brasileiro; sistema processual penal de garantias brasileiro; direito ao contraditório

\section{THE POLICIZATION OF JUSTICE: AN ANALYSIS OF FOUCAULT'S HYPOTHESIS IN THE BRAZILIAN CRIMINAL JUSTICE SYSTEM BASED ON THE RIGHT TO CONTRADICTION}

\begin{abstract}
Based on the hypothesis presented by Michel Foucault that Justice is at the service of the police, this paper intends to answer the question if this assertion is also verified in Brazil, thus constituting its central problem. To carry out a research on the criminal procedural system of guarantees in Brazil, as well as the peculiar forms of information production through evidence according to the criminal procedural designs that are presented in Brazilian judicial practice. Foucault's hypothesis was confirmed because of too much use of information produced in the police phase or by the eighth of police in court decisions.
\end{abstract}

Keywords: Foucaut's hypothesis; policization of justice; Brazilian criminal justice system; criminal system of guarantees; right to contradiction

\section{Introdução}

\footnotetext{
* Professor Titular do IBMEC/RJ; Professor Adjunto do PPGD/UFRJ; Professor Adjunto do PPGD/UCP; Pós Doutorado pela Universidade de Coimbra; Doutor e Mestre pela UFRJ; Mestre pela Universidade de Granada; Advogado criminalista. <antonio.santoro@ucp.br>

** Professora Substituta da UFRJ. Professora visitante do programa de pós graduação da ABDCONST/RJ. Doutoranda em Direito pela UFRJ. Mestra em Direito pela Universidade Católica de Petrópolis (UCP). Especialização em Direito Penal, Processo Penal e Criminologia pela UCAM/RJ. Graduada em Direito pela UERJ. Advogada criminalista. Endereço eletrônico <natalialuceroadv@gmail.com>.
} 
Sob o aspecto metodológico, nos trabalhos de pesquisa o problema proposto antecede a hipótese formulada como solução possível, para então ser definida a metodologia com a qual se pretende colher elementos que conduzam à confirmação ou infirmação da hipótese.

Trabalharemos com o procedimento invertido no presente caso, porquanto a hipótese que dá origem à inquietação que moveu os autores do presente trabalho foi formulada por Michel Foucault quando de sua entrevista intitulada "Michel Foucault par lui même", em 25 de abril de 1977 (FOUCAULT POUR LUI-MÊME, 2003).

Ao ser perguntado qual é a função de um juiz na sociedade, Foucault respondeu que ele serve, no fundo, para fazer a polícia funcionar. Sua compreensão é de que a Justiça é feita para registrar no nível oficial, no nível legal, e ritual também, esses controles de normalização que são assegurados pela polícia. E remata: “a Justiça está a serviço da polícia, historicamente e institucionalmente."

Não resta dúvida que por mais que Michel Foucault fosse um pensador amplamente conhecedor dos sistemas penais de diversas partes do mundo, sua realidade primeira era o sistema francês. Daí porque a hipótese de Foucault ganha relevo e importância para o desenvolvimento de um questionamento brasileiro: no Brasil, a justiça está a serviço da polícia?

Esse é o problema de pesquisa do presente trabalho, cuja hipótese é aquela apresentada pelo próprio Foucault.

Para respondê-la far-se-á uma análise bibliográfica sobre o garantismo penal e a compatibilidade do sistema brasileiro com esta teoria , enfrentar-se-á os dados oficiais sobre prisões e processos criminais no Brasil, mas especialmente far-se-á uma abordagem prática dos desenhos processuais penais brasileiros e das suas peculiares formas de produção de informação pela produção de prova para verificar a compatibilidade com um dos elementos centrais do eixo fundamental de sistema processual penal de garantias: o contraditório.

\section{A adoção pelo Brasil de um modelo garantista de processo penal: os axiomas processuais garantistas pensados por Luigi Ferrajoli e sua compatibilidade com os princípios constitucionais e convencionais brasileiros}

Luigi Ferrajoli, em sua conhecida obra Direito e Razão: teoria do garantismo penal (FERRAJOLI, 2014, p. 91 e ss.), elaborou um sistema teórico baseado em apenas dez 
axiomas básicos. Sem qualquer deles o sistema penal de um país não pode ser, na sua concepção, ser chamado de garantista. Dos dez axiomas, os quatro últimos (A7, A8, A9 e A10) são aqueles que dizem respeito ao processo penal.

Em linhas muito gerais, são esses os axiomas processuais garantistas:

(A7) Nulla culpa sine judicio - princípio da jurisdicionariedade, no sentido lato e estrito - segundo o qual ninguém pode constatar a culpa se não estiver investido formalmente de poderes jurisdicionais e exercido por alguém imparcial (sentido lato), mas também que aquele investido do poder jurisdicional respeite uma série de regras que exigem descrições precisas e impedem o uso de palavras vagas ou valorativas a respeito da verificabilidade ou refutabilidade das teses processuais que enunciam fatos e provas (sentido estrito). A não observância desse axioma torna o sistema punitivo irracional.

(A8) Nullum judicium sine accusatione - princípio acusatório ou da separação entre juiz e acusação - segundo o qual é preciso que haja uma acusação e que o julgador não seja a mesma pessoa do acusador. A não observância desse axioma torna o sistema autoritário, considerado um sistema inquisitório.

(A9) Nulla acusatio sine probatione - princípio do ônus da prova ou da verificação segundo o qual cabe à acusação provar os termos de suas alegações, o que decorre diretamente do princípio da presunção de inocência. A não observância desse axioma torna o sistema autoritário, considerado um sistema de mera legalidade.

(A10) Nulla probatio sine defensione - princípio do contraditório ou da defesa segundo o qual uma decisão pela imposição de punição só é legítima se for garantido ao acusado o direito de se defender. A não observância desse axioma torna o sistema autoritário, considerado também um sistema de mera legalidade.

A separação entre o acusador e o julgador, afastando o sistema inquisitório e adotando o sistema acusatório, conquanto se possa inferir de diversas previsões, decorre diretamente da previsão do artigo 129, inciso I da Constituição. A obrigatoriedade de que a acusação demonstre suas alegações, decorre diretamente da previsão constitucional da presunção de não culpabilidade, artigo $5^{\circ}$, inciso LVI, que termina por atribuir ao órgão de acusação o ônus da prova. $\mathrm{O}$ direito à ampla defesa e ao contraditório estão expressos no inciso LV do artigo $5^{\circ}$ da Constituição.

Portanto, os axiomas 8, 9 e 10, têm expresso assento constitucional. Outra questão é se o axioma 7 também tem. 
Naturalmente a previsão de que ninguém pode ser processado e sentenciado senão pela autoridade competente, constante do artigo $5^{\circ}$, inciso LIII, da Constituição, malgrado não afirme que se trata de autoridade judicial, permite verificar sem grandes dificuldades a satisfação da primeira parte da garantia da jurisdição em sentido lato, mas a exigência de uma investidura imparcial somente pode ser dessumido de diversos dispositivos constitucionais, os quais não expressam literalmente a exigência de imparcialidade.

É na Convenção Americana sobre Direitos Humanos, em seu artigo 8.1, que está expressa a exigência de que todos sejam julgados por uma autoridade com poderes judiciais independente e imparcial.

Também na Convenção Americana sobre Direitos Humanos se expressa o princípio da presunção de inocência no artigo 8.2, já tratado na Constituição como princípio da não culpabilidade. Ainda nesta norma internacional se expressam de maneira mais detalhada (embora não de forma exauriente, por certo) o direito de defesa e o contraditório.

Há, portanto, plena compatibilidade das disposições constitucionais e convencionais com o que Luigi Ferrajoli compreendeu como um sistema penal garantista.

\section{O processo como modelo epistemológico democrático do conhecimento com base empírica}

Um ponto fundamental para o enfrentamento do problema é saber se na prática o sistema processual penal brasileiro, para além da discussão sobre um processo de matiz inquisitória ou acusatória, cumpre aquilo que a Constituição e os Tratados Internacionais sobre Direitos Humanos asseguram.

É dizer, em outras palavras, tal como o fez Geraldo Prado ao tratar o sistema processual penal, distinguindo o aspecto estático e o dinâmico (PRADO, 2005, p. 123 e ss.) saber se o processo penal brasileiro assegura o eixo fundamental de um sistema de garantias, a saber: a presunção de inocência, a imparcialidade do julgador, o direito ao contraditório ${ }^{\dagger}$ e o direito de defesa.

Não pode haver pretensão de discutir, no espaço de um artigo acadêmico, a execução prática de todos os elementos desse eixo. Mas é possível trabalhar alguns deles.

\footnotetext{
${ }^{\dagger}$ Aqui estamos distinguindo o direito de defesa do contraditório, na medida em que o contraditório deve ser garantido também à acusação e o direito de defesa envolve outras questões que estão além do contraditório, como o direito à defesa pessoal.
} 
Dessa forma, mais uma vez tomando as lições de Ferrajoli, do ponto de vista epistemológico, assim como do ponto de vista político ou jurídico, o que se exige é "que a legitimidade das decisões penais se condicione à verdade empírica de suas motivações" (FERRAJOLI, 2014, p. 70).

Essa condição é base da dimensão probatória da presunção de inocência. É dizer, em outras palavras, que se qualquer pessoa acusada é presumida inocente, nenhuma condenação pode estar fundada senão em provas que permitam afastar essa presunção.

O processo, segundo Michele Taruffo, sob uma perspectiva metodológica, pode ser analisado pela sua dimensão epistêmica “como um 'modelo epistemológico' do conhecimento dos fatos com base nas provas" (TARUFFO, 2012, p. 160). E ressalta:

Em todo e qualquer procedimento de caráter epistêmico tem importância decisiva o método, ou seja, o conjunto das modalidades com que são selecionadas, controladas e utilizadas as informações que servem para demonstrar a veracidade das conclusões. No âmbito do processo isso equivale a fazer referência sobretudo às regras que disciplinam a produção das provas e sua utilização, ou seja, ao "direito das provas" e à equivalente noção anglo-americana da law of evidence. (TARUFFO, 2012, p. 164)

Portanto, resta claro que o processo penal se legitima pela busca do conhecimento da verdade com base nas provas.

Certo de que os fatos estão no passado, as provas nada mais são do que signos transmitidos, são materiais semióticos que representam a única via de acesso ao conhecimento (ANDRÉS IBAÑEZ, 2009, p. 49) e que, como em todo procedimento de caráter epistêmico, devem ser obtidas com estrita observância do método de produção e utilização.

Esse método pode determinar especialmente a observância de dois elementos do eixo fundamental de um sistema processual penal de garantias: a imparcialidade e o contraditório.

De forma muito sucinta, é possível abordar a dimensão probatória da imparcialidade. Com efeito, é muito conhecida a crítica que se realiza às regras processuais penais brasileiras quanto à possibilidade de que o juiz produza prova de ofício, tanto no caso de dúvida (artigo 156, inciso II, do CPP), como durante a investigação (artigo 156, inciso I, do CPP). Por essa razão, boa parte dos pesquisadores consideram o processo penal brasileiro inquisitório ou neoinquisitório (LOPES JÚNIOR, 2018, p. 48).

Certo é que não se apresenta possível admitir a imparcialidade do juiz nos casos em que o próprio julgador é quem toma iniciativa de investigar, tampouco pode ser compreendido como imparcial o juiz que na dúvida produz prova de ofício ao invés de aplicar o in dubio pro 
reo. Afinal, se a dúvida milita em favor do réu, qualquer iniciativa que o juiz tome para dirimir sua dúvida que não seja absolver o réu, implica admitir que sua intenção não é absolver, posto que se fosse a solução estaria dada pela distribuição do ônus probatório realizada pelo princípio da presunção de inocência.

No entanto, não menos certo é admitir que as regras infraconstitucionais permitem que um juiz trabalhe fazendo a gestão direta da prova, tomando iniciativa propositiva, mas sua ocorrência prática depende da postura individual de cada juiz. Em outros termos, o sistema admite a atuação parcial do juiz, mas não o torna regra. Isso por si só afasta a imparcialidade como eixo fundamental de um sistema processual penal, de tal forma que não pode ser considerado garantista, mas não significa que todos os juízes ajam de forma parcial. São regras que terminam por subjetivizar a imparcialidade e vulneram o sistema de garantias.

Quanto à dimensão probatória do contraditório, não se pode ignorar que seja possível admitir, mesmo em circunstâncias nas quais a formação da convicção judicial se realize a partir de dados coletados sem passar pelo filtro do contraditório, que exista alguma compatibilidade empírica da decisão com os dados. O problema está exatamente na democraticidade desses dados.

Em contexto como esse (não observância do contraditório), o juiz estaria julgando com base empírica nas evidências, no sentido que é atribuído a este termo por Rui Cunha Martins (2013, p. 159 a 186), que se lhe apresentam à consciência, mas não com base na prova colhida de acordo com a formalidade que impõe o processo penal, incluindo todo regramento necessário para que estes dados adquiram democraticidade e, portanto, possam efetivamente condicionar a decisão penal condenatória com respeito às garantias.

Portanto, o respeito ou desrespeito aos elementos imparcialidade e contraditório do eixo fundamental de um sistema processual penal de garantias precisa ser verificado na prática.

Como já se expôs anteriormente, a imparcialidade resta mitigada e deixada ao subjetivismo casuístico ao admitir-se no sistema brasileiro a iniciativa probatória de parte do juiz.

Em relação ao contraditório, conquanto a Lei $n^{\circ}$ 11.690/2008 tenha estabelecido novos procedimentos probatórios que aproximaram a produção da informação à observância do contraditório, resta saber se na prática isso se realizou. Para tanto serão apresentadas as 
características dos desenhos processuais penais brasileiros e as respectivas peculiaridades na produção dos dados que servem para formar a convicção judicial e fundamentar as decisões.

\section{Processo penal tradicional e o controle social punitivo da pobreza}

Inicialmente deve se proceder à uma desambiguação necessária. O que se chamará aqui de processo penal tradicional não equivale ao modelo clássico de legalidade. $\mathrm{O}$ processo penal tradicional é aqui tratado como aquele que se estabeleceu em suas bases fundamentais a partir do advento da modernidade, mas não se fundamenta no respeito aos direitos humanos.

Como coloca Foucault, no início do século XIX, momento em que definiu como da instauração e funcionamento do grande sistema penal cujas linhas foram dadas na França pelo Código de Instrução Criminal (1808) e do Código Penal (1810), é possível identificar quatro elementos de análise: primeiro, está em curso uma guerra social que não é universal, mas de ricos contra pobres; segundo, as leis são feitas por pessoas às quais elas não se destinam, para serem aplicadas àqueles que não as fizeram; terceiro, o aparato judiciário é comandado pelo princípio da vigilância universal, convertendo o espetáculo em vigilância; quarto, o sistema de reclusão (FOUCAULT, 2015, p. 23).

Foucault percebe que o sistema penal da modernidade, diversamente daquele que se estabelecia na Idade Média, não se dirige ao indivíduo que retira parte do consumo sem trabalhar, mas alguém que afeta a massa global das coisas por consumir, portanto, atinge os mecanismos de produção: o número de trabalhadores, a quantidade de trabalho fornecida e a quantidade de dinheiro que deveria voltar para a terra para fazê-la frutificar. "O vagabundo, portanto, é alguém que perturba a produção, e não só o consumidor estéril" (FOUCAULT, 2015 , p. 44).

Há, assim, a partir do contratualismo, uma compreensão política do criminoso como inimigo da sociedade e, sob o viés econômico, como aquele que se opõe à maximização da produção.

A passagem da política criminal do medievo, que destrói o corpo do condenado, para a do modo de produção capitalista, que poupa o corpo para que na sua produtividade se evidencie o poder econômico, tem no tempo um importante paradigma de afirmação histórica: "do contrato como fixação do tempo de trabalho e da sentença como fixação do tempo de reclusão" (DE GIORGI, 2006, p. 41). 
O cárcere passa a desempenhar um importante papel na ordem de controle capitalista (cf. MELOSSI e PAVARINO, 2010), a ideia de conversão da punição em ressocialização ${ }^{\ddagger}$ e sua guinada ao estado atual do superencarceramento, tanto nos Estados Unidos (Cf WACQUANT, 2003 e, mais especificamente quanto ao viés racista, ALEXANDER, 2017) como no Brasil (SOUZA, 2018), precisam ser considerados para compreensão do impacto sobre o desenho do processo penal que a essa estrutura de controle corresponde.

Mais especificamente em nosso país a assustadoramente crescente taxa de encarceramento se dirige especialmente a pessoas pobres e negras.

De acordo com os dados do "Levantamento Nacional de Informações Penitenciárias INFOPEN" referente ao mês de junho de 2016, a população carcerária brasileira já se apresenta como a terceira maior do mundo ${ }^{\S}$, ao passo que a taxa de pessoas presas por cem mil habitantes passou de 306 para 352,6. Negros e pardos compõem 53\% da população brasileira, mas respondem por $64 \%$ da população prisional. Mais de $60 \%$ dos presos não tem o Ensino Fundamental completo.

Um dado muito relevante para o que se pretende com o presente trabalho é identificar o impacto dos presos provisórios.

Os dados revelam que 40,2\% (quarenta vírgula dois por cento) dos presos são provisórios (INFOPEN, 2016, p. 8). Isso implica dizer que em 2016 havia mais de 292.000 pessoas presas provisoriamente.

Esse é traço característico do superencarceramento brasileiro frente aos países com maior população carcerária é a importância da prisão provisória, assim compreendida não apenas as prisões que têm natureza cautelar, mas toda prisão realizada durante o curso do processo.

Isso se faz ao arrepio de uma política criminal legislativa que caminhou no sentido contrário durante o mesmo período, tendo em vista a entrada em vigor da Lei $\mathrm{n}^{\circ}$ 12.403/2011 que fixou parâmetros mais rígidos para a decretação da prisão preventiva, bem como da criação e implantação da audiência de custódia no Brasil (especialmente a partir de 2015).

\footnotetext{
* Diante de uma ideia de previdenciarismo próprio da proposta do Wellfare State (vide GARLAND, 2008, p. 365-430).

${ }^{\S}$ De acordo com o Levantamento de Informações penitenciárias de junho de 2016 (BRASIL. Levantamento Nacional de Informações Penitenciárias - INFOPEN - junho de 2016. Brasília: Ministério da Justiça, 2017, p. 7 (doravante denominado simplesmente Infopen), o Brasil tem 726.712 presos, a terceira maior população carcerária do mundo. Segundo dados divulgados em $1^{\circ}$ de maio de 2017 pelo Institute for Criminal Policy Research, 622.079 pessoas compõem a população carcerária russa, cifra inferior àquela apresentada pelo sistema prisional brasileiro.
} 
A prisão provisória é, atualmente no Brasil, uma antecipação punitiva determinada e executada para evitar um juízo de desvalor que se exerce sobre o Poder Judiciário compreendido como constituído por uma casta de privilegiados que são remunerados muito acima da população em geral e devem assumir uma responsabilidade maior por isso.

É, portanto, uma atitude que responde à pressão por punição em razão dos discursos de medo (cf. BATISTA, 2009) que são amplamente divulgados e deturpados pela grande mídia (cf. GOMES, 2015) e que estabelecem parâmetros de atuação das agências do sistema penal que não correspondem às suas funções originais no processo penal.

Assim, juízes e promotores ${ }^{* *}$ assumem posições típicas dos agentes de segurança pública e não de sujeitos processuais que são, estabelecendo em conjunto um conflito direto com o acusado, ou seja, ambos estão ao mesmo lado lutando contra o inimigo comum. O prejuízo ao sistema é grande, pois parte da inversão prática do princípio da presunção de inocência, mas ainda maior quando se tem em vista que o juiz, mais especialmente que o promotor, participa ativamente do processo penal que passa a ser usado como o mais importante instrumento para combate ao crime e proteção da sociedade.

Os agentes de segurança pública, por sua vez, se convertem em fontes de prova. É o que ocorre quando policiais militares, que pela estrutura de segurança pública brasileira são os responsáveis pelo policiamento ostensivo, são ouvidos como testemunha e, não raramente, como a única fonte de prova do crime do qual o réu é acusado.

Acresça-se que a práxis ainda converteu o meio de prova que extrai dos agentes de segurança pública (posicionados como fontes de prova), elementos de prova, adotando à sorrelfa um sistema de prova legal que os admite como suficientes para uma condenação. Foi o que fez o Tribunal de Justiça do Rio de Janeiro ao editar a súmula 70, que autoriza a condenação com base exclusivamente no depoimento dos policiais.

Desta forma, e sem pretender exaurir o tema, é possível identificaras características dos desenhos processuais penais de exceção. Pode-se, diante da brevíssima análise que anteriormente foi apresentada, afirmar que o processo penal tradicional no Brasil, utilizado como instrumento para o controle punitivo das classes mais vulneráveis, caracteriza-se por: (1) responder a um discurso midiático do medo; (2) dirigir-se contra as classes que se

\footnotetext{
** Naturalmente a utilização da expressão própria a designar o membro do Ministério Público estadual se deve ao fato de que é essa esfera que responde pelo grande encarceramento de jovens pobres e negros, acusados especialmente de tráfico, roubo, furto e homicídios (que juntos representam mais de 70\% dos tipos penais pelos quais respondem ou foram condenadas as pessoas encarceradas).
} 
constituem especialmente a mão-de-obra para os meios de produção; (3) a antecipação da sanção pelo superuso da prisão provisória; (4) a confusão entre as funções dos sujeitos processuais e dos agentes de segurança pública, atribuindo àqueles às funções destes; (5) a utilização dos agentes de segurança pública como fontes de prova.

Não se pode ignorar que a população carcerária brasileira, repita-se, terceira maior do mundo, é composta de forma amplamente majoritária por pessoas acusadas ou condenadas pela prática de crimes contra o patrimônio (37\%), crime de drogas $(28 \%)$ e crimes contra a pessoa (11\%). Isso significa dizer não apenas que quase $80 \%$ das pessoas presas (em números absolutos são mais de 550 mil pessoas) se submetem a processos com esse desenho supra descrito, como a produção da informação se faz de forma amplamente majoritária durante a investigação.

Com efeito, a utilização dos agentes de segurança pública como fontes de prova é uma realidade em todos os casos, mas ganha especial relevo nos crimes de drogas, cujas apreensões de material ou prisões são realizadas por policiais que servem processualmente como única fonte de informação da autoria.

Por sinal, a súmula 70 do Tribunal de Justiça do Estado do Rio de Janeiro, que empresta validade e idoneidade ao depoimentos de policiais, para definir critério de decidibilidade, sustenta-se não apenas na situação ideal de democraticidade efetiva das agências repressivas, mas também na absoluta falta de outras provas, termina na prática operando como uma regra de decisão mesmo quando outras provas existam (CARVALHO, 2018, p. 239 a 279).

A materialidade dos crimes de drogas é aferida, em geral, pelas apreensões em procedimentos de busca e apreensão, com ou sem mandado (normalmente sem), cujas circunstâncias são descritas pelos policiais que funcionam como fontes de prova que atestam a validade e idoneidade dos seus próprios atos, numa espécie de círculo autoconfirmatório amparado pelo enunciado da súmula 70, anteriormente descrita.

Mesmo nos crimes contra a pessoa, a perícia que atesta a morte ou lesão são produzidos na fase de investigação e terminam fundamentando a condenação amparados pelo permissivo da "prova não repetível", constante do artigo 155 do CPP.

É este mesmo dispositivo que valida a apreensão de drogas realizada como uma prova cautelar, da espécie de meio de obtenção ou de investigação de prova que é a busca e apreensão. 
Resta claro, portanto, que quase $80 \%$ da população prisional brasileira se submete a processos com características do desenho apresentado, em que os dados tomados em conta para o julgamento e fundamentação da decisão condenatória ou da decisão de prisão processual toma em conta prova produzida sem o contraditório direto, seja por provas não repetíveis ou meios de obtenção de prova, como a busca e apreensão, seja por supervaloração do depoimento dos agentes de segurança que atuaram na coleta da informação, convertendoos em fontes de prova.

Mas há paralelamente ao processo penal tradicional, o processo penal de emergência, dirigido ao trato de outra camada da população e com outras finalidades não necessariamente dirigidas à garantia do funcionamento dos meios de produção, mas cujo uso tem muitas vezes viés político. Importa, dessa forma, traçar as características desse desenho processual penal.

\section{Processo penal de emergência: os maxiprocessos e o Lawfare político}

A compreensão do conceito de Lawfare político é de grande valia para empreender o enfrentamento do problema que se propôs.

Em um ensaio do ano de 2001, Charles Dunlap (2001, p. 315) foi quem primeiro utilizou a expressão Lawfare, por influência de outro ensaio, de autoria de David Rivkin e Lee Casey, publicado no ano 2000 (RIVKIN e CASEY, 2003, p. 3/15), em que afirmaram que aliados dos Estados Unidos e adversários escolheram usar o direito internacional como um meio para verificar ou para proteger o poder norte americano.

Dunlap compreende o Lawfare como "a estratégia do uso - ou não uso - do Direito como um substitutivo dos meios militares tradicionais para atingir um objetivo de combate de guerra" (2001). Não tardou para que o Lawfare passasse a ser compreendido como um sucedâneo não apenas de combates de guerra, mas também de embates políticos. ${ }^{\dagger \dagger}$

Nesse sentido e com base na abordagem de Kittrie (2016, p. 8), é possível indicar dois testes para identificar se uma ação ${ }^{\dagger}$ jurídica pode ser qualificada como Lawfare político: (1) o autor (seja uma pessoa ou um grupo político) da ação deve usar o Direito para criar os mesmos ou similares efeitos àqueles tradicionalmente buscados pela ações políticas e (2) a

\footnotetext{
† O que é Lawfare? Disponível em <http://thelawfareproject.org/lawfare/what-is-lawfare-1/>. Acessado em 06 mai 2017.

" Para desambiguar a expressão, deve se frisar que o termo "ação" não está sendo utilizada no sentido técnico processual como sinônimo de "ação judicial", mas no sentido de qualquer ação ou atividade juridicamente fundamentada.
} 
motivação do autor da ação ou de pessoas ou grupos políticos que utilizam a ação deve ser enfraquecer ou destruir um adversário político contra o qual o Lawfare está sendo manejado (SANTORO e TAVARES, 2017, p. 39/40).

Os principais instrumentos para utilização do direito com fins políticos são (a) Iniciativa de criação de novas leis que permitam a redução de garantias no âmbito das persecuções penais; (b) Iniciativa de criação de novas leis com a tipificação aberta que permita a adequação de condutas com finalidade de coibição de ações políticas tidas como criminosas ou que invertam o ônus probatório; (c) Jurisdicionalização de discussões outrora essencialmente reservadas ao campo político; (d) Reinterpretação criativa de leis existentes reduzindo a importância dos direitos humanos e fundamentais; (e) Instaurações de persecuções criminais para alcançar objetivos políticos; (f) Divulgações de persecuções criminais com a afetação de imagens pessoais para alcançar objetivos políticos.

Os dois últimos instrumentos interessam mais a este trabalho, pois que a partir da ideia de que a instauração de persecuções penais pode ser instrumentalizada para alcançar objetivos político, é possível analisar o que Luigi Ferrajoli chamou de "maxiprocessos" (FERRAJOLI, 2014, p. 760).

Luigi Ferrajoli jamais usou a expressão "lawfare" ou fez qualquer referência a estudos sobre esse tema, mas é possível identificar aquilo que ele chama de subsistema penal de exceção como um dos apontados instrumentos de Lawfare político caracterizado como “instauração de persecuções criminais para alcançar objetivos políticos".

Em outras palavras, há uma identidade entre os fundamentos da intervenção punitiva no subsistema de penal de exceção trabalhado por Ferrajoli e os fundamentos da intervenção punitiva usada como instrumento de Lawfare: os objetivos políticos. O que confere legitimidade à punição não é mais a razão “jurídica, mas imediatamente política" (FERRAJOLI, 2014, p. 747).

Nesse contexto, o que Ferrajoli chamou de "razão de Estado" se sobrepõe à "razão jurídica" e não existe mais jurisdição, mas "arbítrio policialesco, repressão política" (FERRAJOLI, 2014, p. 751), incompatível com o Estado de direito. Entre as mais relevantes 
alterações no modelo clássico de legalidade penal nos processos de emergência (FERRAJOLI, 2014, p. 758 e ss) estão o que ele denominou de maxiprocessos ${ }^{\S \S}$.

Assim, com inspiração nas lições de Ferrajoli, é possível traçar as mais importantes características dos maxiprocessos: (1) cobertura midiática massiva; (2) o gigantismo processual (FERRAJOLI, 2014, p. 760); (3) a confusão processual; (4) a mutação substancial do modelo clássico de legalidade penal; (5) o incremento da utilização dos meios investigação ou obtenção de prova.

A primeira característica, denominada (1) "cobertura midiática massiva" dos maxiprocessos, diversamente do que ocorre com o processo penal tradicional, não utiliza o discurso do medo (cf. BATISTA, 2009), que termina por apresentar implicações especialmente na segurança pública, mas se vale do discurso da impunidade ${ }^{* * *}$ e gera três consequências básicas: (i) espetaculariza os eventos originados de investigações e processos criminais (cf. CASARA, 2016), (ii) confere publicidade opressiva aos julgamentos criminais interferindo no direito ao um processo justo (cf. SCHREIBER, 2008) e (iii) determina a agenda dos órgãos atuantes na justiça criminal (cf. MCCOMBS, 1972).

A segunda característica dos maxiprocessos, o (2) "gigantismo processual", pode ser (i) horizontal (gigantismo processual horizontal), caracterizado pela abertura de "megainvestigações contra centenas de imputados, mediante prisões baseadas em frágeis indícios como primeiros e prejudiciais atos de instrução" (FERRAJOLI, 2014, p. 760/761); (ii) vertical (gigantismo processual vertical), que se verifica pela multiplicação de imputações realizadas sobre as mesmas pessoas, com delitos associativos gerando imputações específicas e vice-versa, circularmente; (iii) temporal (gigantismo processual temporal), com processos que se arrastam por anos acompanhados do cumprimento de penas por meio de prisões preventivas ou afastamento de direitos fundamentais (FERRAJOLI, 2011, p. 89 e ss) por categorias processuais antes do efetivo julgamento.

A terceira característica, denominada (3) "confusão processual" se apresenta de forma subjetiva (confusão processual subjetiva) e/ou objetiva (confusão processual objetiva).

A confusão processual subjetiva se caracteriza quando a polícia exerce funções tipicamente judiciais (SANTORO e ORTIGÃO, 2016) ou quando o juiz exerce funções

\footnotetext{
$\$$ A expressão maxiprocessos é extraída de FERRAJOLI, 2014, p. 760 e ss. que o situa em uma espécie de direito penal especial ou de exceção. O termo também pode ser encontrada em ALFONSO e CENTONE, 2011. Tratando como "megajustiça" confira-se PRATES, 2016.

**** Que também é um discurso a serviço do processo penal tradicional. A esse respeito cf. GENELHÚ, 2015.
} 
policialescas, tal como a atribuição de tarefas e instrumentos investigativos aos julgadores, como, por exemplo, quando a lei brasileira (art. $1^{\circ}$ da Lei $\left.{ }^{\circ} 9.296 / 96\right)$ atribui ao juiz poderes para determinar uma interceptação telefônica de ofício. Tendo em vista a "natural parcialidade da polícia em relação à imparcialidade institucional do juiz" (FERRAJOLI, 2014, p. 762), a confusão subjetiva coloca em xeque um axioma básico do processo penal justo, que é a imparcialidade ${ }^{\dagger \dagger \dagger}$.

A confusão processual objetiva é característica atribuível aos maxiprocessos. É uma confusão entre processos supostamente diversos ou entre processos e investigações, que terminam por tratar de temas ou fatos parcial ou quase integralmente idênticos, gerando novas investigações a partir de processos criminais.

Essa característica da confusão processual objetiva entre investigações e processos implica na potencialização da confusão processual subjetiva, não apenas porque os magistrados exercem funções tipicamente investigativas, mas porque o fazem em um processo para instruir outra(s) investigação(ões) que o terão como julgador em razão da regra da prevenção positiva ${ }^{\text {t+. }}$.

Apontada como mais importante alteração das técnicas punitivas características dos maxiprocessos por Ferrajoli, a característica chamada de (4) "mutação substancial do modelo clássico de legalidade penal” consiste na utilização do 'paradigma do inimigo' (FERRAJOLI, 2014, p. 758/759), o que exprime uma personalização do sistema penal. Em outras palavras, um direito penal do réu e não do crime.

A utilização de figuras típicas associativas (como a Organização Criminosa definida pela Lei $\mathrm{n}^{\mathrm{o}}$ 12.850/2013 no Brasil), fórmulas indeterminadas, interpretações elásticas, subjetivas, ideológicas e valorativas, e, por fim, uma predileção por investigar pessoas, ao invés de fatos, identificam essa importante característica dos maxiprocessos (FERRAJOLI, 2014, p. 758/759).

Em decorrência da mutação substancial do modelo de legalidade penal, com a alteração do paradigma de um processo penal do crime para o processo penal do réu, o julgador assume uma posição protagonista, "o juiz torna-se inimigo do réu (...) e não procura a verdade do fato, mas procura no prisioneiro o delito" (FERRAJOLI, 2014, p. 759),

\footnotetext{
${ }^{\dagger \dagger}$ Esse é um tema que tem direta relação com questão da contaminação do julgador com atos do inquérito, cf. LOPES JR., 2006, p. 234 e ss.

\$+ Para uma crítica à prevenção positiva cf. MAYA, 2014.
} 
permitindo ao magistrado invadir a esfera de privacidade do inimigo, por meio de interceptações e buscas domiciliares.

Essa pessoalização da justiça criminal, que muda o paradigma do crime como centro do sistema para o criminoso, antagonizando-o ao juiz, cria o ambiente para a seletividade política ou ideológica do réu, uma vez que no subsistema penal de exceção a intervenção punitiva se legitima no alcance de objetivos políticos.

Há também, na mutação substancial, uma ontologização do crime como um mal, algo moralizante ou pecaminoso, que de forma coerente procura uma confissão e uma “colaboração mediante denúncia dos coautores" (FERRAJOLI, 2014, p. 759) ou mesmo uma confissão à sorrelfa, sem alertas de garantia do direito ao silêncio, como na interceptação telefônica, cujo saldo final é uma pseudo escolha anticriminal, porém confirmatória da hipótese investigatória.

O protagonismo judicial como estratégia para abreviar a confirmação da hipótese investigatória implica com clareza na confusão processual, tanto subjetiva como objetiva, uma vez que o resultado precede o processo e, não raro, é antecipado pela cobertura midiática de forma apriorística à própria investigação, cujos atos ostensivos de delações, interceptações, conduções, buscas e prisões são apenas a face espetacularizada do que já se havia como certo.

Por fim, a última característica, e mais importante para a análise empreendida nesse trabalho, consiste no (5) incremento da utilização dos meios de investigação ou obtenção de prova. É uma característica que decorre naturalmente da mutação substancial e da confusão processual, mas guarda especial relação com a cobertura midiática massiva.

Meios de investigação de prova ou meios de obtenção de prova ou meios de pesquisa de prova se caracterizam por (i) serem instrumentos ou atividades extraprocessuais, (ii) que podem ser produzidos na fase investigatória (e normalmente o são), (iii) sem a participação do investigado e da defesa, (iv) mas com a participação do juiz (v) baseado no fator surpresa ${ }^{\S \S \S}$, por isso, não há contraditório direto ${ }^{* * * * *}$, (vi) não podem ser repetidos. Diferem dos meios de prova tradicionais que são endoprocessuais, produzidos em juízo, sob o crivo do contraditório direto, com a participação do acusado e sua defesa e, normalmente, podem ser repetidos.

\footnotetext{
$\$ \$$ Chamando-os de métodos ocultos cf. PRADO, 2014.

***** Uma crítica ao uso do contraditório diferido nas interceptações telefônicas SANTORO e RANGEL, 2015. Duas propostas de estabelecimento do contraditório da interceptação telefônica: CASTRO; ABATH e ROSENBLATT, 2016 e CÂMARA, 2016.
} 
Há, portanto, diante desta quinta característica, uma produção antecipada de informação válida para julgamento antes de serem aplicáveis as garantias processuais, com a participação ativa do juiz, aproximando os maxiprocessos de uma lógica tipicamente inquisitiva.

Como o artigo 155 do CPP permite a utilização de provas cautelares para fundamentar a decisão condenatória, verifica-se que a maior parte dos dados nos quais os magistrados formam seu convencimento e justificam suas decisões nos maxiprocessos são obtidos sem o contraditório direto, sendo validadas apenas em caráter formal por um contraditório diferido, na prática um arremedo de contraditório.

\section{Conclusão: o esvaziamento do direito ao contraditório, o superempoderamento da etapa inquisitiva da persecução e a confirmação da hipótese de Foucault}

O artigo 155 do CPP, cuja redação foi dada pela Lei 11.690/2008, criou uma mera aparência de vínculo da formação do convencimento judicial com a prova produzida em contraditório. Isso porque a criação de exceções terminou por reduzir o contraditório à letra morta da Constituição.

O referido dispositivo, conquanto vincule a formação da convicção judicial às provas produzidas em contraditório judicial, admite que o juiz fundamente sua decisão nos elementos informativos colhidos na investigação, desde que não seja exclusivamente. Em outras palavras, pode fundamentar, mas deve ser feito em conjunto com qualquer outra prova produzida em contraditório judicial.

O problema é que a redação do dispositivo ainda termina por fazer uma ressalva que não foi compreendida como um complemento, mas uma nova exceção. É que ao ressalvar as provas cautelares, não repetíveis e antecipadas, o legislador criou condições para que os magistrados decidissem apenas com base nos atos de inquérito, desde que estes sejam caracterizados como provas cautelares, não repetíveis e antecipadas.

Para além da análise formal do conteúdo do artigo 155 do CPP, é possível identificar nos desenhos processuais de exceção do direito processual penal brasileiro, que os dados ou informações utilizadas pelos magistrados para julgamento das causas são essencialmente obtidos sem ou com grave déficit de contraditório. 
Com efeito, no processo penal tradicional, as buscas e apreensões de drogas são executadas na fase de investigação (por vezes é o que deflagra a investigação), com ou sem ordem judicial, e, considerados meios de obtenção de prova, estão acobertados pelo permissivo da prova cautelar; os laudos de exame cadavérico ou exames de corpo de delito para aferir lesões são realizados durante a investigação, sem qualquer participação do investigado e são utilizados como fundamentos condenatórios por se tratarem de provas não repetíveis; na determinação da autoria, não apenas, mas em especial no caso de drogas, o depoimentos dos agentes de segurança pública (policiais militares) convertidos em fontes de prova que autoconfirmam suas atuações enquanto agentes de segurança pública estão amparados por uma pseudo submissão ao contraditório e prévia admissão de validade e idoneidade pela jurisprudência (vide súmula 70 do TJERJ).

Os maxiprocessos superutilizam os meios de obtenção de prova, a saber: busca e apreensão, interceptação telefônica, colaboração premiada, ação controlada, entre outras, em que não há contraditório direto e a submissão ao contraditório diferido não confere ao acusado qualquer poder dialético sobre o conteúdo da informação produzida.

Essa redução do contraditório de um elemento do eixo fundamental do sistema processual penal de garantias para um elemento fungível, passível de ser substituído por inúmeras exceções no âmbito da produção probatória, ou por um arremedo de contraditório (diferido) apenas para travestir o dado probatório de validade, permitem confirmar a hipótese de Foucault.

Ora, se os dados colhidos na fase policial da persecução ou apresentados na fase judicial por um policial é porque a Justiça serve para fazer a polícia funcionar, dar legalidade a um ritual policial de seleção do que e como será julgado. É dizer, em outras palavras, aquelas do próprio Foucault: "a Justiça está a serviço da polícia, historicamente e institucionalmente.”

\section{Bibliografia}

ALEXANDER, Michelle. A nova segregação: racismo e encarceramento em massa. São Paulo: Boitempo, 2017.

ALFONSO, Roberto; CENTONE, Alessandro (a cura di). Fenomenologia del maxiprocesso: venti anni di esperienze. Milão: Giuffreé, 2011. 
ANDRÉS IBÁÑEZ, Perfecto. Prueba y convicción judicial en el proceso penal. Buenos Aires: Hammurabi, 2009.

BATISTA, Vera Malaguti. O medo na cidade do Rio de Janeiro. Rio de Janeiro: Revan, 2009.

BRASIL. Levantamento Nacional de Informações Penitenciárias - INFOPEN - junho de 2016. Brasília: Ministério da Justiça, 2017

CÂMARA, Jorge Luis. A inserção da interceptação telefônica em um sistema acusatório coerente com a centralidade do direito de defesa. In: SANTORO, Antonio Eduardo Ramires; MADURO, Flávio Mirza (org.). Interceptação Telefônica: os 20 anos da Lei $\mathbf{n}^{\circ}$ 9.296/96. Belo Horizonte: D’Plácido, 2016.

CASARA, Rubens. Processo Penal do Espetáculo: ensaios sobre o poder penal, a dogmática e o autoritarismo na sociedade brasileira. Curitiba: Emporio do Direito, 2016.

CASTRO, Helena Rocha Coutinho de; ABATH, Manuela; ROSENBLATT, Fernanda Fonseca. Por uma investigaçãoo preliminar democrática: o contraditório na interceptação telefônica. In: SANTORO, Antonio Eduardo Ramires; MADURO, Flávio Mirza (org.). Interceptação Telefônica: os 20 anos da Lei nº 9.296/96. Belo Horizonte: D’Plácido, 2016.

DE GIORGI, Alessandro. A miséria governada através do sistema penal. Tradução Sérgio Lamarão. Rio de Janeiro: Revan, 2006, p. 41.

DUNLAP JR., Charles J. Lawfare Today and Tomorrow in: International Law and Changing Character of War. Raul A. Pete Pedrozo e Daria P. Wollsschlaeger editores, p. $315 . \quad$ Disponível em http://scholarship.law.duke.edu/cgi/viewcontent.cgi?article=3090\&context=faculty_scholarsh ip. Acessado em 06 mai 2017.

FERRAJOLI, Luigi. Direito e Razão: Teoria do Garantismo Penal. $4^{a}$ edição. Tradutores Ana Paula Zomer Sica, Fauzi Hassan Choukr, Juarez Tavares e Luiz Flávio Gomes.São Paulo: RT, 2014.

FERRAJOLI, Luigi. Por uma teoria dos direitos e dos bens fundamentais. Traduçao Alexandre Salim, Alfredo Copetti Neto, Daniela Cademartori, Hermes Zaneti Júnior, Sérgio Cademartori. Porto Alegre: Livraria do Advogado, 2011, p. 89 e ss.

FERRAJOLI, Luigi. Democracia y Garantismo. Madrid: Editorial Trotta, 2008.

FOUCAULT, Michel. A sociedade punitiva. Tradução Ivone Benedetti. São Paulo: Martins Fontes, 2015.

FOUCAULT POUR LUI-MÊME. Dirigido por Phillippe Calderon. Co-Produção Arte e BFC Productions, 2003, son., cor. (122min) 
GARLAND, David. A cultura do controle: crime e ordem social na sociedade contemporânea. Rio de Janeiro: Revan, 2008.

GENELHÚ, Ricardo. Do discurso da impunidade à impunização: o sistema penal do capitalism brasileiro e a destruição da democracia. Rio de Janeiro: Revan, 2015.

KITTRIE, Orde F. Lawfare: law as a weapon of war. New York: Oxford University Press, 2016.

LOPES JR., Aury. Sistemas de Investigação Preliminar no processo penal. $4^{\mathrm{a}}$ edição. Rio de Janeiro: Lumen Juris, 2006.

MARTINS, Rui Cunha. O ponto cego do direito. São Paulo: Atlas, 2013.

MAYA, André Machado. Imparcialidade e processo penal: da prevenção da competencia ao juiz das garantias. 2a ed. São Paulo: Atlas, 2014.

MELOSSI, Dario e PAVARINI, Massimo. Cárcere e Fábrica: as origens do sistema penitenciário (séculos XVI - XIX). Tradução Sérgio Lamarão. 2a edição. Rio de Janeiro: Revan, 2010.

MCCOMBS, Maxwell E., SHAW, Donald L. The agenda-setting function of mass media. Chicago: University of Chicago Press, 1972.

PRADO, Geraldo. Prova penal e sistema de controles epistêmicos: a quebra da cadeia de custódia das provas obtidas por métodos ocultos. São Paulo: Marcial Pons, 2014.

PRATES, Fernanda. Práticas de interceptação e os riscos do modelo de "megajustiça". In: SANTORO, Antonio Eduardo Ramires; MADURO, Flávio Mirza (org.). Interceptação Telefônica: os 20 anos da Lei no 9.296/96. Belo Horizonte: D’Plácido, 2016.

RIVKIN, David B. e CASEY, Lee A. The Rocky Shoals of International Law. In: WOOLSEY, James (organizador). National Interest on International Law and Order. Nova Jersey: Transaction Publisher, 2003.

SANTORO, Antonio Eduardo Ramires e TAVARES, Natália Lucero Frias. Impeachmt de 2016: uma estratégia de lawfare politico instrumental. Belo Horizonte: D’Plácido, 2017.

SANTORO, Antonio Eduardo Ramires; ORTIGÃO, Francisco Ramalho. Os "hermeneutas do grampo": uma disfucionalidade epistêmica. In: CONPEDI LAW REVIEW, v. 2, n. 1, p. 163/180, jan/jun 2016.

SANTORO, Antonio Eduardo Ramires; RANGEL, Natália. O princípio constitucional do contraditório na interceptação das comunicações telefônicas. In: MENDES, Soraia da Rosa e LONGO, Ana Carolina F. (org.). Segurança Pública. Brasília: IDP, 2015.

SCHREIBER. Simone. A publicidade opressiva de julgamentos criminais. Rio de Janeiro: Renovar, 2008. 
SOUZA, Taiguara Libano Soares e. A era do grande encarceramento. Rio de Janeiro: Revan, 2018.

SUTHERLAND, Edwin. Crime de colarinho branco. Tradução Clécio Lemos. Rio de Janeiro: Revan, 2015.

TARUFFO, Michele. Uma simples verdade: o juiz e a construção dos fatos. Tradução Vitor de Paula Ramos. São Paulo: Marcial Pons, 2012.

WACQUANT, Loïc. Punir os pobres: a nova gestão da miséria nos Estados Unidos [A onda punitiva]. Rio de Janeiro: Revan, 2003. 